
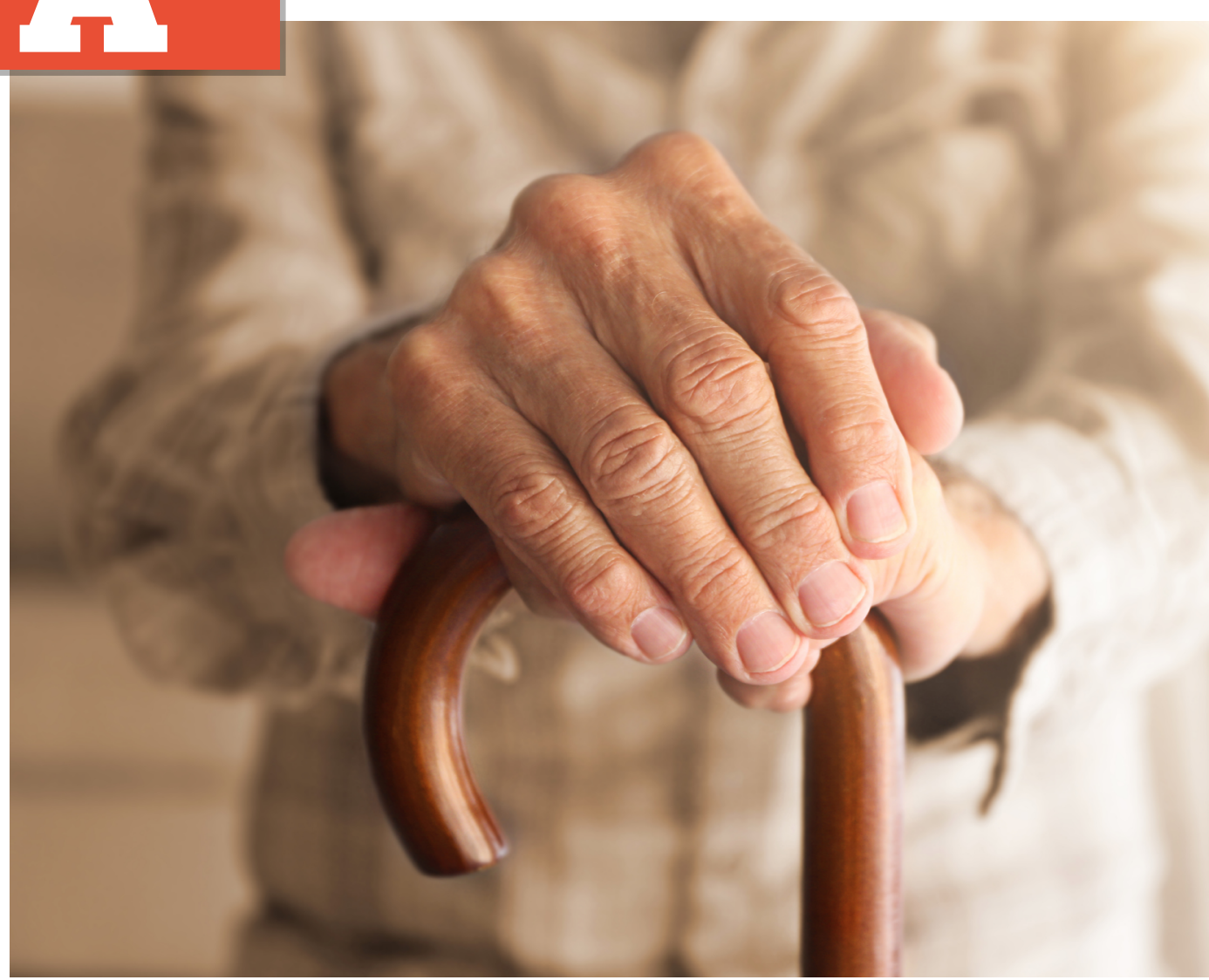

\title{
OS IDOSOS NA AGENDA GOVERNAMENTAL
}

\section{AS MUDANÇAS NA PIRÂMIDE ETÁRIA BRASILEIRA REQUEREM POLÍTICAS PÚBLICAS INOVADORAS QUE CONSIDEREM A HETEROGENEIDADE DA POPULAÇÃO COM MAIS DE 65 ANOS.}

\section{| POR FERNANDO BURGOS}

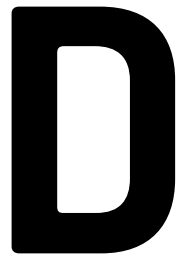

urante os últimos trinta anos, uma das maiores incumbências dos formuladores de políticas públicas nos governos locais brasileiros foi garantir o acesso à educação. Embora ainda existam lacunas nesse tema, a nova geração de gestores públicos enfrentará um desafio diferente nos próximos anos. Em vez de construção de creches, provavelmente, a demanda será por novos centros de acolhimento ou de convivência para idosos, além de outras políticas mais inovadoras para esse público. Isso porque a pirâmide etária brasileira vem se alterando muito rapidamente. Se em 2000 apenas $5,8 \%$ da população brasileira tinha acima de 65 anos, a projeção da população do país calculada pela Gerência de Estudos e Análises da Dinâmica Demográfica 
do Instituto Brasileiro de Geografia e Estatística (IBGE) indica que esse percentual chegará a quase $22 \%$ em 2050. Os idosos com mais de 80 anos, que representavam apenas $1,5 \%$ da população brasileira em 2010 , corresponderão a 6,5\% dos habitantes do país em 2050, ultrapassando 15 milhões de cidadãos (veja no gráfico da página seguinte).

Um aspecto fundamental no debate de políticas públicas para essas faixas etárias é reconhecer que os grupos de idosos são heterogêneos. Há idosos com excelente saúde e adeptos às atividades físicas diárias, enquanto há outros com saúde debilitada e restrições de mobilidade; há aqueles com alta escolaridade formal e outros analfabetos; e, em um país com tanta desigualdade socioeconômica, há os que estão com situação financeira tranquila e os que passam por dificuldades, mesmo para morar e se alimentar. Tratá-los como um conjunto uniforme é um equívoco que não poderá ser cometido pelos novos gestores públicos e empresariais, afinal o modelo one size fits all tende a não atender a ninguém de maneira satisfatória.

Considerando o crescimento da população mais velha e sua diversidade, é insuficiente restringir as ações governamentais, como se fazia há algumas décadas, às áreas de saúde e, no caso dos cidadãos mais vulneráveis economicamente, à assistência social. Sem dúvida, saúde e assistência social permanecem importantes, mas os idosos requerem ações, projetos e políticas em áreas como educação, cultura, esporte, lazer, desenvolvimento econômico, ciência e tecnologia, habitação, transporte, entre outras. Mais do que isso, demandam ações intersetoriais, que envolvam e integrem várias áreas, como também o chamado terceiro setor e o setor empresarial.

Em termos de legislação, um dos maiores avanços no Brasil ocorreu em 2003, com a aprovação do Estatuto do Idoso, que em seu artigo $3^{\circ}$ é claro: "É obrigação da família, da comunidade, da sociedade e do Poder Público assegurar ao idoso, com absoluta prioridade, a efetivação do direito à vida, à saúde, à alimentação, à educação, à cultura, ao esporte, ao lazer, ao trabalho, à cidadania, à liberdade, à dignidade, ao respeito e à convivência familiar e comunitária". Após mais de 15 anos da entrada em vigor do Estatuto do Idoso, ainda há muitas dúvidas e desafios para a efetivação desses direitos. Enquanto isso, a população idosa segue aumentando, o que demanda cotidianamente políticas públicas inovadoras.

\section{INICIATIVAS PELO MUNDO}

Dado que a maioria dos países desenvolvidos já passou por essas questões há algumas décadas, é fundamental que olhemos para o que fizeram. Não se trata de copiar, pois os contextos são diferentes, mas essas experiências - nacionais e locais - podem nos inspirar. Em 2016, a Organização Mundial da Saúde (OMS) adotou uma estratégia global e um plano de ação buscando promover o envelhecimento saudável, entendido como o processo de desenvolvimento e manutenção da capacidade funcional que possibilita o bem-estar na idade mais velha. Para colaborar com os governos, a OMS criou uma rede global de cidades amigáveis aos idosos, chamada de Global Network for Age-friendly Cities and Communities, composta atualmente de mais de 830 cidades e comunidades em 41 países.

No Brasil, apenas seis municípios fazem parte da rede atualmente: Balneário Camboriú, Esteio, Jaguariúna, Pato Branco, Porto Alegre e Veranópolis. Todos ficam no Sul do país, exceto Jaguariúna, localizado no interior de São Paulo. São municípios que vêm lançando iniciativas para atender à variedade de interesses e necessidades do público idoso, do combate à violência doméstica à criação de universidades e atividades esportivas e recreacionais para a população mais velha.

Nas iniciativas internacionais, cabe destacar aspectos nem sempre óbvios que fazem diferença. Um deles é a convivência intergeracional. Trata-se de um dos eixos temáticos que pautam o planejamento de ações do município de Barcelona para as pessoas com mais de 65 anos, que representam $21,6 \%$ da população. A ideia de convivência intergeracional permite combater o chamado ageismo, isto é, os estereótipos negativos e a discriminação por idade. A professora Ana Maria Goldani, da Princeton University, argumenta que se trata de um problema que a sociedade deve enfrentar por meio de conscientização, educação e intervenção política, a fim de buscar a igualdade universal. A discriminação por idade tem implicações importantes para a saúde e o bem-estar das pessoas idosas e impõe barreiras ao desenvolvimento de boas políticas e práticas sobre o envelhecimento.

Outro aspecto que merece atenção é um olhar para quem cuida dos mais velhos. Bons cuidadores tendem a melhorar a qualidade de vida do idoso. No Uruguai, por exemplo, assim como no Brasil, 95\% das pessoas que trabalham como cuidadoras são mulheres. Frequentemente, o trabalho do cuidador do idoso não é remunerado, recaindo sobre filhas, sobrinhas ou netas. Ou, quando remunerado, geralmente é desvalorizado. Para ajudar na profissionalização e na valorização, o sistema de cuidados uruguaio oferece um curso básico de atenção a dependentes, com 90 horas de duração, para pessoas que já atuam ou desejam atuar na área. Além disso, quem já possui mais de cinco anos de experiência pode participar de um processo de certificação de competências laborais.

Em 2015, foi promulgada no Uruguai uma lei federal que criou o Sistema Nacional Integrado de Cuidados (SNIC), 


\section{CRESCIMENTO DA POPULAÇÃO IDOSA NO BRASIL}
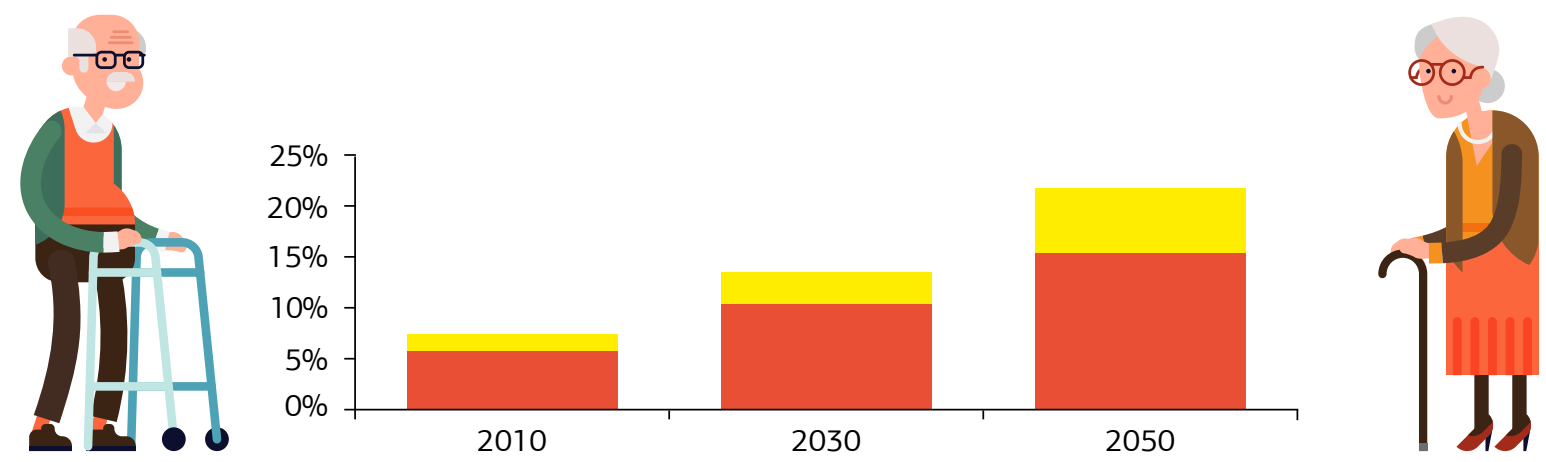

65-79 anos

80 anos ou mais

cujo objetivo era gerar um modelo de corresponsabilização dos cuidados entre famílias, Estado, comunidade e mercado para todas as crianças, pessoas com deficiências e pessoas idosas em situação de dependência. Um sistema integrado de cuidados, como o de Barcelona, além de aumentar a qualidade de vida, pode também evitar a solidão dos idosos. Esse é um último aspecto destacado neste artigo. Em Barcelona, três em cada dez pessoas maiores de 75 anos vivem sozinhas. No Reino Unido, estima-se que mais de 200 mil pessoas idosas não conversam com um amigo ou parente há mais de um mês.

Em 2018, foi lançada a primeira estratégia de enfrentamento à solidão do Reino Unido e um fundo com aporte inicial de 11,5 milhões de libras para financiar projetos ligados à questão. No lançamento, que incluiu vários atores, a ex-primeira-ministra Theresa May mostrou que $75 \%$ dos médicos consultados em pesquisa recente disseram que de uma a cinco pessoas atendidas por dia sofrem de solidão, o que está associado a uma série de impactos prejudiciais à saúde, como doenças cardíacas, derrames e mal de Alzheimer. Uma das ações previstas na estratégia é a prescrição social, para que clínicos gerais direcionem os pacientes a atividades e trabalhos comunitários, em vez de recorrer apenas a tratamentos medicamentosos. Também na linha de construir conexões, foi estabelecida uma parceria com o serviço de correios, que prevê visitas dos entregadores de Liverpool, New Malden e Whitby a pessoas solitárias, como parte de suas rotas de entrega habituais, para ajudar a conectá-las com o apoio de suas famílias ou comunidades, se necessário.

\section{PENSANDO NO FUTURO}

Lidar com as novas demandas oriundas do envelhecimento populacional é algo complexo em razão do cenário de restrições orçamentárias dos governos. Quando o envelhecimento ocorre com o aumento da solidão - normalmente associada a características de identidade, personalidade e condições de saúde, mas agravada com as mudanças no mundo do trabalho, uso intensivo de tecnologia e alterações nas relações familiares -, torna-se ainda mais complexo. Nesse sentido, os municípios e estados brasileiros, assim como o governo federal, precisam urgentemente inserir o tema dos idosos na agenda governamental. As soluções do passado, como centros-dia ou centros de acolhimento, não atendem satisfatoriamente às pessoas com mais de 65 anos. A ideia de envelhecimento ativo e saudável está cada vez mais presente na sociedade. O setor empresarial está atento a isso e já oferece, para os que podem pagar, uma gama variada de serviços, considerando os diversos tipos de idosos. Agora é hora de formular e implementar políticas públicas inovadoras e que considerem a heterogeneidade dos brasileiros mais velhos.

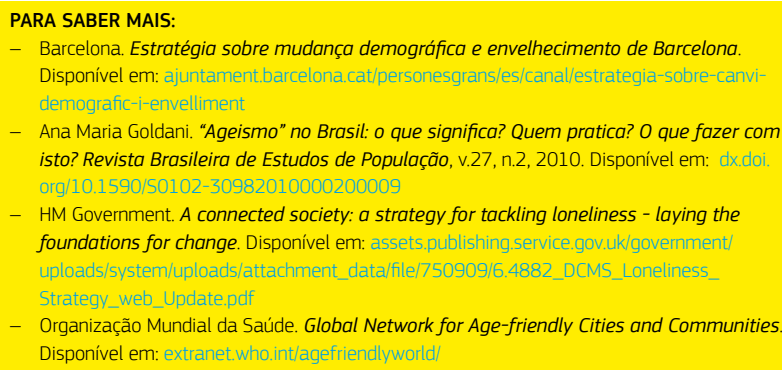

FERNANDO BURGOS > Professor da FGV EAESP e coordenador do Centro de Estudos em Administração Pública e Governo (CEAPG/FGV EAESP) >

fernando.burgos@fgv.br 